ISSN: 2536-5339

\title{
Eskrime Özgü Görsel Reaksiyon Simülasyon Testi İle Denge, Anaerobik Güç ve Görsel Reaksiyon Parametreleri Arasındaki İlişkisinin İncelenmesi
}

\author{
Tuğba KOCAHAN ${ }^{1}$ \\ Burak ÜSTÜNDAĞ ${ }^{1}$ \\ Erkan TORTU ${ }^{1}$ \\ Gökhan DELICEOĞLU ${ }^{2}$ \\ ${ }^{1}$ Gençlik ve Spor Bakanlığı Spor Genel Müdürlüğ̈̈ Sağlık Işleri Dairesi Başkanlığı, ANKARA \\ ${ }^{2}$ Kırıkkale Üniversitesi Spor Bilimleri Fakültesi, KIRIKKALE
}

Künye: Kocahan, T., Üstündağ, B., Tortu, E. ve Deliceoğlu, G. (2018). Eskrime Özgü Görsel Reaksiyon Simülasyon Testi İle Denge, Anaerobik Güç ve Görsel Reaksiyon Parametreleri Arasındaki İlişkisinin İncelenmesi. Gaziantep Üniversitesi Spor Bilimleri Dergisi, 3(4): 169-180.

\section{Öz}

Çalışmanın amacı eskrim branşındaki erkek ve kadın sporcuların, eskrime özgü görsel reaksiyon simülasyon testi ile denge, anaerobik güç ve görsel reaksiyon parametreleri arasındaki ilişkinin incelenmesidir. Araştırma grubunu 9 erkek $\left(X_{\text {yaş }}=18,67 \pm 2,61\right.$ yıl; $\left.X_{\mathrm{va}}=72,17 \pm 12,89 \mathrm{~kg} ; \quad X_{\text {bu }}=178,95 \pm 6,11 \quad \mathrm{~cm}\right), 6$ kadın $\left(X_{\text {yaş }}=17,75 \pm 2,53 \quad\right.$ yıl; $\left.X_{v a}=59,30 \pm 8,39 \mathrm{~kg} ; \quad X_{b u}=164,79 \pm 3,98 \mathrm{~cm}\right)$ toplam 15 elit eskrim sporcuları oluşturmuştur. Araştırma grubuna görsel reaksiyon ölçümü için Witty-Sem görsel reaksiyon test cihazı, denge ölçümü için Y-Blance test platformu, anaerobik güç parametrelerini ölçmek için Monark Ergonometrik 894 E marka bisiklet ergometresi kullanılarak Wingate anaerobik güç testi (WANT) yapılmıştır. Sporcuların ölçülen parametrelerdeki anlamlı farklılığı belirlemek için SPSS 17.0 paket programında Mann Whitney u testi, parametreler arasındaki ilişkinin belirlenmesinde corelasyon testi uygulanmıştır. Erkek ve kadın sporcuların eskrime özgü görsel reaksiyon simülasyon testi ile denge, görsel reaksiyon ve anaerobik güç parametreleri arasında anterior yönde denge ölçümü dışında tüm parametrelerde istatistiksel olarak anlamlı bir farklılık görülmektedir $(p<0,05)$. Korelasyon ölçümüne bakıldığında eskrime özgü planlı ve plansız reaksiyon simülasyon testi ile görsel reaksiyon testi arasında pozitif yönde ilişki bulunurken diğer parametrelerle negatif yönde bir ilişki bulunmuştur. Sonuç olarak yapılan araştırmada erkek ve kadın sporcuların eskrime özgü görsel reaksiyon simülasyon testi ile denge, görsel reaksiyon ve anaerobik güç parametrelerinde erkek sporcular daha iyi değerler elde etmiştir. Parametreler arasındaki ilişkiye bakıldığında ters orantı bulunması ölçülen parametrelerde özellikle denge performansının gelişmesi, reaksiyon süresinin de gelişebileceğini göstermektedir.

Anahtar Kelimeler: Görsel reaksiyon, denge, anaerobik güç parametreleri

\section{Orijinal Makale}

Yayın Bilgileri

Gönderi Tarihi: 20.09.2018

Kabul Tarihi: 11.12.2018

Yayın Tarihi: 28.12.2018

Sorumlu Yazar

e-mail: deliceoglugokhan@kku.edu.tr

DOI: $10.31680 /$ gaunjss.461874 


\section{Examination Of The Relationship Between Fencing-Specific Visual Reaction Simulation Test And Balance, Anaerobic Power And Visual Reaction}

\section{Parameters}

\begin{abstract}
The aim of this study is to examine the relationship between the visual reaction simulation test and the balance, anaerobic power and visual reaction parameters of male and female athletes in fencing branch. The research group have formed that 9 Male (Xage $=18,67 \pm 2.61$ years; Xbw $=72,17 \pm 12.89 \mathrm{~kg} ; X_{\text {length }}=178,95 \pm 6.11 \mathrm{~cm}$ ), 6 female (Xage $=17,75 \pm 2.53$ years; $X b w=59,30 \pm 8.39 \mathrm{~kg} ; X_{\text {length }}=164,79 \pm 3.98 \mathrm{~cm}$ ) 15 elite fencing athletes. The Study Group was tested using the witty-sem visual reaction test device for Visual reaction measurement, $y$-blance test platform for balance measurement, and the Wingate anaerobic power test using the Monark Ergonomometer 894 E Brand Bicycle ergometer to measure anaerobic power parameters. In the SPSS 17.0 package program, Mann Whitney u test was used to determine the correlation between the parameters. There was a statistically significant difference between male and female athletes ' simulated reaction and balance, visual reaction and anaerobic power parameters in all parameters except the anterior direction balance measurement $(p<0.05)$. When we look at the correlation measurement, there was a positive correlation between the simulated and unplanned reaction simulation test and the Visual reaction test, and there was a negative correlation with other parameters.
\end{abstract}

Keywords: Visual reaction, balance, anaerobic power

\section{Original Article}

Article Info

Received: 20.09 .2018

Accepted: 11.12 .2018

Published: 28.12.2018

Corresponding Author

e-mail: deliceoglugokhan@kku.edu.tr

\section{Giriş}

Eskrim, iki sporcunun silah ile dolaylı bir mücadele yaptığı, yüksek beceri gerektiren aralıklı ve yüklenme temelli bir spor dalı ve sporculara fiziksel, zihinsel özelliklerini en iyi şekilde kullanma imkanı veren, kendine özgü tekniği ve inceliği olan, sinir sistemi üzerinde düzenlemeyi sağlayan, özellikle görme ve elle dokunma hislerinin koordinasyonunu (göz-kas koordinasyonu) geliştiren, denge özelliği ile vücudun değişik yerlerine en geniş ölçüde uzanma ve gerilme imkanı veren, anaerobik güç parametreleriyle kasların çabuk harekete geçmesini, gerektiğinde tekrarlanmasını kolayca sağlayan, çabukluğun, çabuk kuvvetin ve reaksiyon zamanının öncelik taşıdığı, bir spordur (Enzo, 1985; Auxter ve ark., 1993).

Eskrim de teknik ve taktiğe ek olarak, reaksiyon zamanı önemli rol oynamaktadır. Reaksiyon zamanı, karar verme hızı ile yakından ilişkilidir (Duvan ve ark., 2010). Alınan uyarıya karşı cevap oluşturulup harekete geçilmesi arasındaki zaman, reaksiyon zamanı olarak tanımlanmaktadır (Sevim, 2002). Fiziksel aktivitenin etkisi ile reaksiyon zamanı 11-14 yaşları arasında yüksek gelişim gösterirken, 15 yaşlarında en yüksek seviyesine erişir ve gelişimi tamamlanır (Muratlı, 2007).

Alan yazında reaksiyon zamanının iki parça halinde incelenebileceği üzerinde durulmuştur. Uyarının alınmasıyla kas aktivitesinin başlangıcı arasında geçen bir süre 
reaksiyon süresinin birinci parçasıdır ve "motor öncesi süre" olarak adlandırılır. Íkinci parçası ise kas aktivitesi artışında vücut parçasının görülen hareketine kadar geçen süredir ve "motor süre" olarak adlandırılır. Motor öncesi süre, gelen bilginin merkezi sinir sistemindeki işlemi ile kasta hareketin başlaması arasında ki süreyi belirtmektedir. Bu zaman aralığı, hareket meydana gelmeden, gözle görülen herhangi bir hareketin olmadığı karar verme aşamasıdır. Yani uyarının belirlenmesinden, potansiyel kas hareketinin değişikliğine kadar geçen süreyi kapsamaktadır. Motor süre olarak adlandırılan dönem ise potansiyel kas hareketinden, gözle görülür gerçek hareketin başlamasına kadar geçen zamandır (Ün, 2003).

Birçok spor branşında yapılan hareketin patlayıcı formda sergilenebilmesi performansın göstergesi olarak karşımıza çıkarken, anaerobik performans patlayıcı formda kısa süreli ve yüksek şiddetli uygulamaların temel belirleyicisi olmaktadır (Şahin, 2016). Kısa zaman biriminde, büyük oranda güç üretebilme yeteneği olarak tarif edilen anaerobik güç eskrim spor dalında her hamle hareketinde oldukça ağır olan vücudu ileri götürmek, geri getirmek ve tekrarını sağlamak için büyük kas gruplarının çalışmasıyla ortaya çıkmaktadır (Arseven, 1976).

Anaerobik performansla birlikte sporcunun maksimal kuvvetini kullanabilmesi ve optimal düzeyde performansa çevirebilmesi için belirli bir kas dengesine intiyacı vardır. Kas dengesi bir kas veya kas grubuyla bunu karşılayan, ters yönde hareket sağlayan kas veya kas grubuyla ilişkilidir (Baecchle ve Earl, 2000).

Denge, kavramsal tanımı olarak, bir nesnenin veya bir insanın devrilmeden durma hâli, fiziksel tanım olarak ise, birbirini ortadan kaldıran güçlerin sonucu olan durma halidir. Denge, hareket ve dinlenme esnasında yerçekimine karşı gösterilen vücut kompozisyonuna uyumdur (Sandrey, 2006). Bu yetenek, özellikle vücudun ağırlık merkezinin değişmesi nedeniyle dengenin bozulması gibi, dar dayanma alanlarının olduğu ve dengenin kolaylıkla bozulabileceği koşullarda ortaya çıkan motorik sorunları çözmeye yarar. Denge; statik denge ve dinamik denge olmak üzere ikiye ayrılarak da incelenebilir. Statik denge; vücudun dengesini belli bir yerde ya da pozisyonda sağlama yeteneği iken, dinamik denge; hareket ederken vücudun dengesini sağlama yeteneğidir (Hazar, 2008)

Bu bilgiler ışığında eskrime özgü görsel reaksiyon ile denge, anaerobik güç ve görsel reaksiyon parametreleri arasındaki ilişinin belirlenmesi amacıyla bu çalışma yapılmıştır. 


\section{Yöntem}

$\mathrm{Bu}$ bölümde araştırma grubunun özellikleri veri toplama araçları, verilerin toplanması ve verilerin analizi açıklanmıştır.

\section{Araştırma grubu}

Araştırma grubunun yaş (yı), vücut ağırlığı $(\mathrm{kg})$ ve boy $(\mathrm{cm})$ uzunluğuna ait veriler Tablo 1'de belirtilmiştir.

Tablo 1. Sporcuların Fiziksel Özellikleri

\begin{tabular}{cccccccc}
\hline \multirow{2}{*}{ Araştırma Grubu } & N & \multicolumn{2}{c}{ Yaş (yıl) } & \multicolumn{2}{c}{ Vücut ağırlığı (kg) } & \multicolumn{2}{c}{ Boy uzunluğu (cm) } \\
& & X & SS & X & SS & X & SS \\
\hline Erkek & 9 & 18,67 & 2,61 & 72,17 & 12,89 & 178,95 & 6,11 \\
\hline Kadın & 6 & 17,75 & 2,53 & 59,30 & 8,39 & 164,79 & \multirow{2}{*}{3,98} \\
\hline
\end{tabular}

\section{Veri toplama araçları}

Testlere katılan sporcuların boy uzunlukları Charder marka mezura, vücut ağırıkları Tanita MC-980MA Japon marka baskül, görsel reaksiyon simülasyon testi ve görsel reaksiyon ölçümleri için Witty-Sem görsel reaksiyon test cihazı, anaerobik güç parametrelerini ölçmek için Monark Ergonometrik 894 E marka bisiklet ergometresi kullanılarak Wingate anaerobik güç testi ve denge ölçümü için Y-Blance test platformu kullanılmıştır.

\section{Verilerin toplanması}

Testlere katılan sporcuların boy uzunlukları anatomik duruşta, çıplak ayak, ayak topukları birleşik, nefesini tutmuş, baş frontal düzlemde, baş üstü tablası verteks noktasına değecek şekilde pozisyon alındıktan sonra, ölçüm 'cm' olarak ölçülmüş, vücut ağırıkları ise sadece şortla, çıplak ayak ve anatomik duruş pozisyonunda iken 'kg' olarak ölçülmüştür (Başpınar, 2009).

\section{Eskrime özgü görsel reaksiyon simülasyon testi}

Eskrimcilerin görsel uyarana karşı verdikleri tepkinin süresinin ölçülmesi amacıyla eskrim müsabakasının simule edildiği modifiye görsel reaksiyon testi planlanmıştır. Planlı görsel reaksiyon simülasyon testinde "A" uyaran merkezde olacak şekilde ve her seferinde bu uyarana hamle yapması istenen sporcunun bütün 
uyaranları sırasıyla (A, B, C, D, E, F, G ve H) kapatması istenmiştir. İki kez alınan bu ölçüm sonrasında sporculara bilgi verilmeden plansız (random) görsel reaksiyon simülasyon testi yapılmış yerleri değiştirilen uyarıcıların kapatılması istenmiştir.

\section{Görsel reaksiyon testi}

Reaksiyon zamanlarının ölçülmesinde ölçüm yapılan yerin gürültüsüz ve ışık alan bir ortam olması dikkate alınmıştır. Görsel reaksiyon ölçümünde sporculara Witty-Sem reaksiyon test cihazına ait bir pano üzerine sabitlenmiş 8 lamba üzerinde rastgele yanan renkler arasından mavi rengi yakalamaları istenmiş ve 60 adet tekrar sonrasında test sonlandırımıştır. 2 deneme sonucunda en iyi ölçüm değerlendirmeye alınmıştır (Pehlivan Çavuş ve ark. 2017)

\section{Denge testi}

Denge ölçümü " $Y$ Balance Test" platformu üzerinde çıplak ayak olarak uygulanmıştır. Daima sağ ayağın üzerinde başlayan sporcular başlangıç çizgisinin gerisinde, tek ayak üzerinde dengede dururken, diğer ayağının parmak ucu ile 3 yöne (anterior, postero-medial ve posterolateral) uzanması istendi. Test, her yön için 15 sn'lik dinlenme aralıkları ile $3 \mathrm{kez}$ tekrarlandı, en iyi skor $\mathrm{cm}$ cinsinden kaydedildi. Test cihazında, anterior, posterior doğrultular arasında $135^{\circ}$, posterior doğrultular arasında ise $90^{\circ}$ lik acı vardır. Her iki bacak için de üç farklı yönde yapılan en iyi derece değerlendirmeye alınmıştır (Gür Kabul ve ark. 2018).

\section{Wingate anaerobik güç testi}

Wingate anaerobik güç testi (WAnT) için modifiye edilmiş bilgisayara bağlı ve uyumlu bir yazılımla çalışan kefeli bir bisiklet ergometresi (Monark $894 \mathrm{E}$, Sweeden) kullanılmıştır. Testler öncesi her sporcu için sele ve pedal boyu ayarları yapılmıştır. Bacak wingate testinde vücut ağırlığının $\% 7,5$ 'ine karşılık gelen ağırlık bilgisayarda otomatik olarak hesaplanmış ve bisikletin kefesine yerleştirilmiştir (Özkan, 2010).

Uygulanan test süresince ölçümler otomatik olarak beş saniyede bir altı eşit zaman aralığında yapılmıs ve bu ölçümler sonucunda anaerobik performans ile ilgili bazı veriler elde edilmiştir. Test süresince, herhangi bir beş saniyelik zaman dilimi içerisinde elde edilen en yüksek güç Anaerobik Güç (AG), test süresince meydana getirilen ortalama güç Anaerobik Kapasite (AK), olarak açıklanmaktadır (Özkan, 2007; Yücel, 2015). 
WAnT'ne başlamadan önce sporcular $5 \mathrm{dk}$ boyunca bisiklette ısınma amaçlı pedal çevirmişlerdir (60-80 Rpm arası) (Rpm: Pedal çevirme hızı). Her 1 dakikanın son 5 saniyesinde son hız yüklenme yaptırımıştır (120-160 Rpm arası). Isınma tamamlandıktan sonra 2 dakika streching (germe) yaptııımış ve sporcunun toparlanması sağlanmıştır. Sporcu hazır olduğu anda başla komutu verildikten sonra, test başlamış ve 30 saniye boyunca sporcu sözlü olarak teşvik edilmiştir. Test bittikten sonra sporcu 3 dakika boyunca düşük hızda soğuma amaçlı pedal çevirmeye devam etmiş ve test sonlandırılmıştır (Yücel, 2015).

\section{Verilerin analizi}

Eskrim sporcularının parametrelerdeki anlamlı farklııı̆ını belirlemek için SPSS 17.0 paket programında Mann-Whitney $U$ testi, parametreler arasındaki ilişkinin belirlenmesinde korelasyon testi uygulanmıştır. Anlamlılık düzeyi için $\mathrm{P}<0,05$ kullanılmıştır.

\section{Bulgular}

$\mathrm{Bu}$ bölümde, erkek ve kadın eskrim sporcularının ölçümü yapılan parametrelere ilişkin bulgular ve bulgulara dayalı olarak yapılan yorumlara yer verilmiştir.

Araştırma grubunun görsel reaksiyon ölçümüne ilişkin Mann Whitney U Testi değerleri aşağıdaki tablo 2'de belirtilmiştir.

Tablo 2. Erkek ve Kadın Eskrim Sporcularının Görsel Reaksiyon Değerleri

\begin{tabular}{ccccccc}
\hline Gruplar & Cinsiyet & N & X & SS & U & p \\
\hline \multirow{2}{*}{ Görsel Reaksiyon } & Erkek & 9 & 41.66 & 5.86 & 8.00 &, $025^{\star}$ \\
& Kadın & 6 & 48.66 & & \\
\hline
\end{tabular}

Tablo 2 incelendiğinde erkek ve kadın eskrim sporcuların görsel reaksiyon ölçümünde istatistiksel olarak anlamlı bir farklılık bulunmuştur $(P<0,05)$. Bu bulguya göre erkek sporcuların görsel reaksiyon değerlerinin daha iyi olduğu söylenebilir.

Araştırma grubunun denge ölçümüne ilişkin Mann Whitney $U$ Testi değerleri aşağıdaki tablo 3 'de belirtilmiş̧ir. 
Tablo 3. Erkek ve Kadın Eskrim Sporcularının Denge Değerleri

\begin{tabular}{|c|c|c|c|c|c|c|}
\hline Gruplar & Cinsiyet & $\mathbf{N}$ & $x$ & ss & $\mathbf{U}$ & $\mathbf{p}$ \\
\hline Denge Ant.Sağ & $\begin{array}{l}\text { Erkek } \\
\text { Kadın }\end{array}$ & $\begin{array}{l}9 \\
6\end{array}$ & $\begin{array}{l}66.88 \\
63.66\end{array}$ & 4.95 & 17.5 & ,261 \\
\hline Denge Ant.Sol & $\begin{array}{l}\text { Erkek } \\
\text { Kadın }\end{array}$ & $\begin{array}{l}9 \\
6\end{array}$ & $\begin{array}{l}67.00 \\
64.83\end{array}$ & 5.62 & 18.5 & ,314 \\
\hline Denge Ptm.Sağ & $\begin{array}{l}\text { Erkek } \\
\text { Kadın }\end{array}$ & $\begin{array}{l}9 \\
6\end{array}$ & $\begin{array}{l}112,44 \\
103.50\end{array}$ & 7.82 & 9.00 & ,033* \\
\hline Denge Ptm.Sol & $\begin{array}{l}\text { Erkek } \\
\text { Kadın }\end{array}$ & $\begin{array}{l}9 \\
6\end{array}$ & $\begin{array}{l}113.11 \\
102.50\end{array}$ & 9.15 & 8.00 &, $025^{*}$ \\
\hline Denge Ptı.Sağ & $\begin{array}{l}\text { Erkek } \\
\text { Kadın }\end{array}$ & $\begin{array}{l}9 \\
6\end{array}$ & $\begin{array}{l}109.66 \\
100.33\end{array}$ & 7.82 & 9.00 &, $032^{*}$ \\
\hline Denge Ptl.Sol & $\begin{array}{l}\text { Erkek } \\
\text { Kadın }\end{array}$ & $\begin{array}{l}9 \\
6\end{array}$ & $\begin{array}{l}109.55 \\
102.00\end{array}$ & 7.94 & 10.0 &, $045^{\star}$ \\
\hline
\end{tabular}

Tablo 3 incelendiğinde erkek ve kadın eskrim sporcuların denge ölçümünde anterior yönde denge ölçümü dışında erkekler lehine istatistiksel olarak anlamlı bir farklılık bulunmuştur $(P<0,05)$. Bu bulguya göre erkek eskrim sporcularının daha iyi değerler elde ettiği görülmektedir.

Araştırma grubunun anaerobik performans ölçümüne ilişkin Mann Whitney $U$ Testi değerleri aşağıdaki tablo 4'de belirtilmiştir.

Tablo 4. Erkek ve Kadın Eskrim Sporcularının Anaerobik Performans Değerleri

\begin{tabular}{|c|c|c|c|c|c|c|}
\hline Gruplar & Cinsiyet & $\mathbf{N}$ & $x$ & SS & $\mathbf{U}$ & $\mathbf{p}$ \\
\hline Anaerobik PP (W) & $\begin{array}{l}\text { Erkek } \\
\text { Kadın }\end{array}$ & $\begin{array}{l}9 \\
6\end{array}$ & $\begin{array}{c}1032.00 \\
626.16\end{array}$ & 256.2 & 2.00 &, $003^{*}$ \\
\hline Anaerobik AP (W) & $\begin{array}{l}\text { Erkek } \\
\text { Kadın }\end{array}$ & $\begin{array}{l}9 \\
6\end{array}$ & $\begin{array}{l}649.11 \\
448.00\end{array}$ & 136.8 & 4.00 &, $007^{*}$ \\
\hline
\end{tabular}

Tablo 4 incelendiğinde erkek ve kadın eskrim sporcuların anaerobik performans ölçümünde istatistiksel olarak anlamlı bir farklılık bulunmuştur $(P<0,05)$. Bu bulguya göre erkek eskrim sporcularının anaerobik güç değerlerinin daha iyi olduğu söylenebilir.

Araştırma grubunun görsel reaksiyon simülasyon ölçümüne ilişkin Mann Whitney U Testi değerleri aşağıdaki tablo 5'de belirtilmiştir. 
Tablo 5. Erkek ve Kadın Eskrim Sporcularının Görsel Reaksiyon Değerleri

\begin{tabular}{|c|c|c|c|c|c|c|}
\hline Gruplar & Cinsiyet & $\mathbf{N}$ & $x$ & SS & $\mathbf{U}$ & p \\
\hline Simülasyon Planlı & $\begin{array}{l}\text { Erkek } \\
\text { Kadın }\end{array}$ & $\begin{array}{l}9 \\
6\end{array}$ & $\begin{array}{l}23.22 \\
25.33\end{array}$ & 1.94 & 9.50 & ,029* \\
\hline Simülasyon Plansız & $\begin{array}{l}\text { Erkek } \\
\text { Kadın }\end{array}$ & $\begin{array}{l}9 \\
6\end{array}$ & $\begin{array}{l}24.55 \\
27.33\end{array}$ & 2.25 & 7.00 &, $017^{*}$ \\
\hline
\end{tabular}

Tablo 5 incelendiğinde erkek ve kadın eskrim sporcuların görsel reaksiyon simülasyon ölçümünde istatistiksel olarak anlamlı bir farklılık bulunmuştur $(P<0,05)$. $\mathrm{Bu}$ bulguya göre erkek eskrim sporcularının simülasyon planlı ve plansız görsel reaksiyon değerlerinin daha iyi olduğu söylenebilir.

Korelasyon sonuçlarına bakıldığında eskrime özgü planlı ve plansız reaksiyon simülasyon testi ile görsel reaksiyon testi arasında pozitif yönde ilişki bulunurken, denge ve anaerobik parametrelerde negatif yönde ilişki bulunmuştur. Eskrime özgü planlı reaksiyon simülasyon testiyle en yüksek ilişki posterolateral sağ denge ölçümü $(-, 756)$ ile bulunurken planlı reaksiyon simülasyon değişkeniyle en düşük ilişki anaerobik kapasite $(-, 375)$ arasında bulunmuştur. Eskrime özgü plansız reaksiyon simülasyon testi ile en yüksek ilişki posteromedial sol denge ölçümü $(-, 732)$ ile bulunurken plansız reaksiyon simülasyon testiyle en düşük ilişki anaerobik kapasite $(-, 416)$ arasında bulunmuştur.

$\mathrm{Bu}$ bulgular ışığında planlı ve plansız reaksiyon simülasyon testleriyle tüm parametreler arasında negatif ilişki görülürken en yüksek ilişki denge testinde ölçülmüştür. Reaksiyon testiyle ise doğrusal bir ilişki belirlenmiştir. Parametreler arasında simülasyon testleriyle en düşük ilişki düzeyi anaerobik kapasite arasında saptanmıştır.

\section{Tartışma ve Sonuç}

Yapılan çalışmada erkek ve kadın sporcuların eskrime özgü görsel reaksiyon simülasyon testi ile denge, görsel reaksiyon ve anaerobik güç parametreleri arasında anterior yönde denge ölçümü dışında tüm parametrelerde istatistiksel olarak anlamlı bir farklılık görülmektedir ( $p<0.05)$.

Reaksiyon üzerine yapılan benzer çalışmalar incelendiğinde; Duvan ve ark. (2010) erkek ve kadın eskrimcilerin maksimal yüklenme yoğunluğunda görsel reaksiyon zamanlarının (erkek= 231,22 \pm 19,13 $\mathrm{ms}$, kadın= 285,02 \pm 44,27 ms),

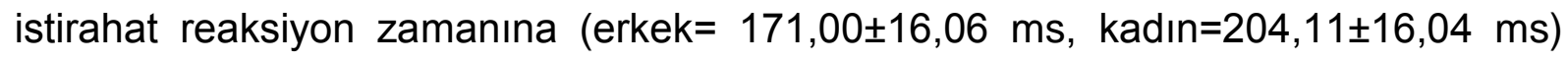


göre daha uzun olduğu tespit edildiği çalışmasında erkek sporcuların reaksiyon zamanı ortalamasının kadın sporculara göre daha iyi olduğu belirlenmiştir.

İspanya eskrim ve karate milli takımında yer alan sporcular üzerinde yapılan

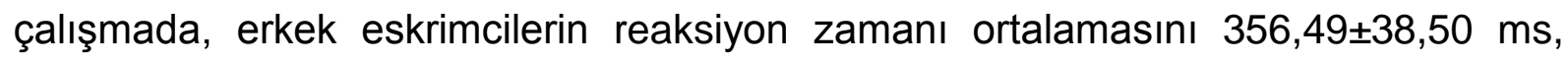
kadın eskrimcilerin reaksiyon zamanı ortalamasını $397,11 \pm 32,11 \mathrm{~ms}$, erkek karatecilerin reaksiyon zamanı ortalamasını 399,00 $\pm 72,50 \mathrm{~ms}$, kadın karatecilerin reaksiyon zamanı ortalamasını 396,84 $\pm 30,23$ ms olarak tespit etmişlerdir (Di russo ve ark.2006).

Altınok (2011) çift yönlü varyans test sonuçlarına göre eskrimcilerin cinsiyete göre ortalama reaksiyon süre dereceleri arasındaki farkın anlamlı olduğu $\left(F_{(1,120)}=9.267 ; P<0.05\right)$ belirlenmiştir. Erkeklerin ortalama reaksiyon süre derecesinin $(0.67 \pm 0.011 \mathrm{sn})$ kızlardan $(0.71 \pm 0.011 \mathrm{sn})$ daha iyi olduğu belirlenmiştir. Görsel reaksiyon ölçümlerinde çalışmamıza benzer araştırmalara rastlanmıştır.

Anaerobik performans üzerine yapılan benzer çalışmalar incelendiğinde; araştırmalar erkeklerin anaerobik performansının mutlak değerler yönünden kadınlardan daha yüksek olduğu tespit edilmiş ve relatif değerler yönünden incelendiğinde bazı çalışmalarda, bu çalışmaların bulgularına benzer şekilde cinsiyetler arası farklılıkların azalmakla beraber devam ettiği anlaşılmıştır (Ozan, 2013). Murphy ve ark (1986) mutlak anaerobik performans değerlerini erkeklerde kadınlara göre sırasıyla \%35 ve \%40, Esbjörnsson ve ark (1993) ise \%48 ve \%44 oranında daha yüksek bulurken Koşar ve Kin İşler (2004) çalışmalarında erkek öğrencilerin mutlak anaerobik performans değerleri kız öğrencilerinkinden sırasıyla $\% 50$ ve $\% 47$ daha yüksek bulmuşlardır.

Çimen ve ark., (1997) yaşları 16-19 arasında değişen 10 erkek, 10 bayan genç milli masa tenisçi ile yaptığı çalışmada erkek sporcuların anaerobik güç değerleri bayan sporculara göre daha yüksek bulunmuştur.

Bir başka çalışmada ise $10 \mathrm{sn}$. 20sn. ve 90sn.' lik yapılan anaerobik performans testlerinde erkeklerin performans değerlerinin kadınlara oranla daha yüksek olduğu saptanmıştır (Bouchard ve ark., 1991). Anaerobik performans ölçümlerinde çalışmamızla benzer sonuçlara rastlanmıştır.

Denge üzerine yapılan benzer çalışmalar incelendiğinde; Denerel (2011), sporcular üzerinde yaptığı bir çalışmanın sonucunda, erkeklerde vücut kitle indeksi, kadınlarda sadece kilonun denge skorunu olumsuz etkilediğini tespit etmiştir. 
Göktepe (2016) 6 erkek, 6 kadın milli atlet, 7 erkek, 7 kadın milli kayakçı, Ağrı İbrahim Çeçen Üniversitesinde öğrenim gören 14 erkek, 11 kadın sedanter yine okul takımlarında oynayan 28 erkek, 9 kadın futbolcu, 8 erkek, 6 kadın hentbolcu olmak üzere toplam 77 sporcu 25 sedanterle yapmış olduğu çalışmasında;

Sporcularda statik denge değerleri sedanterlerden daha iyi olduğu, erkek deneklerde en iyi performansın futbolcularda daha sonra sırasıyla atletizm, hentbol, kayak ve sedanterlerde olduğu, kadın deneklerde ise en iyi performansın hentbolcularda daha sonra sırasıyla futbol, atletizm, kayak ve sedanterlerde olduğu tespit edilmiştir.

Dinamik denge değerleri ise erkek sporcuların erkek sedanterlere göre daha iyi olduğu, fakat kadın sporcuların kadın sedanterlerle birbirine çok yakın olduğu tespit edilmiştir. Erkek deneklerde en iyi performansın atletlerde daha sonra sırasıyla, kayak, futbol, hentbol ve sedanterlerde olduğu, kadın deneklerde ise ortalama değerlerin birbirine çok yakın olduğu tespit edilmiştir. Fakat erkek ve bayan sporcularda vücut kompozisyonu ile statik ve dinamik denge arasında ilişkinin olmadığı sonucuna varılmıştır. Denge ölçümlerinde bizim çalışmamıza benzer şekilde araştırmalar görülmüştür.

Elde edilen parametreler arasındaki ilişkilere ait sonuçlara benzer literatürde araştırmalara rastlanmamıştır. Tartışma kısmı incelendiğinde hareketlerin uygulanma süresindeki kuvvet yetisinde iyi olan erkek eskrimcilerin bu özelliklerini denge, görsel reaksiyon ve anaerobik güç parametrelerine aktarabildiği düşünülmektedir.

Sonuç olarak erkek ve kadın sporcuların eskrime özgü görsel reaksiyon simülasyon testi ile denge, görsel reaksiyon ve anaerobik güç parametrelerinde erkek sporcular daha iyi değerler elde etmiştir. Parametreler arasındaki ilişkiye bakıldığında özellikle denge performansının gelişmesi, reaksiyon süresinin de gelişeceğini göstermektedir.

\section{Kaynaklar}

Altınok B. (2011). Kılıç Epe ve Flöre Dallarında Üst Düzeyde Spor Yapan Bayan ve Erkek Eskrimcilerin Temel Biyomotor Dayanıklıık ve Vücut Yağ Yüzdelerinin Araştırılması. Yüksek Lisans Tezi, Dumlupınar Üniversitesi.

Arseven R. (1976). Eskrim Tarihi ve Modern Eskrim. İstanbul, s. 89, 21-22.

Auxter D., Pyfer J., Hunettig C. (1993). Adapted Physical Education and Reaction. 7. Ed. Mosby, USA. 
Baecchle T.R. Earle R.W. (2000). Plyometric Training, Potach, D. H. \& Chu, D. A.(Der.). Essential of Strength Training and Conditioning, Canada, Human Kinetics.

Başpınar Ö. (2009). Futbolcularda İzokinetik Kas Kuvvetinin Anaerobik Güce Etkisi.

Yüksek Lisans Tezi, Pamukkale Üniversitesi, Denizli.

Bouchard C., Taylor A. W., Simaneau J., Dulac S. (1991). Testing Anaerobic Power and Capacity. (L MacDouall, H. A Wenger, H Gren Ed.). Physiological Testing of the High Performance Athlete. Champaign, IL: Human Kinetics Books, 175221.

Çimen O., Cicilioğlu İ., Günay M. (1997). Erkek ve Bayan Türk Genç Milli Masa Tenisçilerinin Fiziksel ve Fizyolojik Profilleri. Beden Eğitimi Spor Bilimleri Dergisi II, $4: 7$-12.

Denerel H. N. (2011). Statik ve Dinamik Germe Egzersizlerinin Dinamik Denge Üzerine Akut Etkisi. Tıpta Uzmanlık Tezi. İzmir, Ege Üniversitesi Tıp Fakültesi.

Di Russo F., Taddei F., Apnile T., Spinelli D. (2006). Neural Correlates Of Fast Stimulus Discrimination And Response Selection In Top-Level Fencers. Neurosci Lett, 13;408(2):113-8.

Duvan A., Toros T., Şenel Ö. (2010). Maksimal Yüklenme Yoğunluğunun Elit Türk Eskrimcilerin Görsel Reaksiyon Zamanları Üzerine Etkisi. Niğde Üniversitesi Beden Eğitimi ve Spor Bilimleri Dergisi, 4-3.

Enzo M.G. (1985). Cours International Pour Technicsien D'escrime, Roma, s.2.

Esbjörnsson M., Sylven C., Holm I., Jansson E. (1993). Fast Twitch Fibers May Predict Anaerobic Performance in Both Females and Males. International Journal of Sports Medicine. 14 (5): 263.

Göktepe M., Şenel Ö., Özkan A. (2015). Bazı Raket Sporlarıyla Uğraşan Sporcuların Reaksiyon Zamanları ve El Kavrama Kuvvetleri İle Denge ve Proprioseptif Duyularının İlişkisi. Uluslararası Hakemli Akademik Spor Sağlık ve Tıp Bilimleri Dergisi, Sayı: 17, Ss, 1-25.

Gür K. E., Başakçı Ç. B., Baş A. U., Ünver F. (2018). Sağlıklı Gençlerde Kısa Dönem Dinamik Stabilizasyon Eğitiminin Esneklik, Kassal Endurans ve Dinamik Denge Üzerine Etkileri. Journal of Exercise Therapy and Rehabilitation 5-1.

Hazar F., Taşmektepligil Y. (2008). Puberte Öncesi Dönemde Denge ve Esnekliğin Çeviklik Üzerine Etkilerinin İncelenmesi. SPORMETRE Beden Eğitimi ve Spor Bilimleri Dergisi, VI (1) 9-12. 
Koşar N., Kin İ. A. (2004). Üniversite Öğrencilerinin Wingate Anaerobic Performans Profili ve Cinsiyet Farklılıkları. Hacettepe Üniversitesi, Ankara. Spor Bilimleri Dergisi. 15 (1): 25-38.

Muratı S. (2007). Antrenman Bilimi Yaklaşımıyla Çocuk ve Spor. Nobel Basımevi, 2.baskı, 212-216, Ankara.

Murphy M. M., Patton J. F., Frederick F. A. (1986). Comparative Anaerobic Power of Men and Women. Aviat Space Environ Med, 57 (7): 636-641.

Özkan A., Kin İ. A. (2010). Sporcularda Bacak Hacmi, Kütlesi, Hamstring/Quadriceps Oranı İle Anaerobik Performans ve İzokinetik Bacak Kuvveti Arasındaki İlişki. Spor Bilimleri Dergisi Hacettepe, 21 (3), 90-102.

Özkan A. (2007). Wingate Anaerobik Güç Testinde Optimal Yükün Belirlenmesi, Yüksek Lisans Tezi, Hacettepe Üniversitesi, Ankara.

Pehlivan Ç. T., Deliceoğlu G., Tortu E., Kocahan T. (2017). İşitme Engelli Judo ve Judo Milli Takım Sporcularının Görsel Reaksiyon ve Denge Yetilerinin Karşılaştırılması. 15. Uluslararası Spor Bilimleri Kongresi.

Sandrey M. A. (2006). The Comparative Effects Of A Six-Week Balance Training Program, Gluteus Medius Strength training Program, And Combined Balance Training/Gluteus Medius Strength Training Program On Dynamic Postural Control, Master Of Science In Athletic Training, School Of Physical Education, Morgantown, West Virginia.

Sevim Y. (2002). Antrenman Bilgisi, Nobel Yayın Dağıtım, 1. Baskı, 76-78, Ankara.

Şahin Y. (2016). Eskrimcilerde Dominant- Non Dominant Bacak Kuvvetlerinin Araştırılması. Yüksek Lisans Tezi, Selçuk Üniversitesi, Konya.

Ün N. (2003). Zihinsel Özürlü Çocuklarda Fiziksel Uygunluk Eğitiminin Reaksiyon Zamanı Üzerine Etkisi. H.Ü. Sağ. Bil. Enst., Doktora Tezi, Ankara.

Yücel B. (2015). Takım Sporlarında Kuvvet Antrenmanlarının Anaerobik Güç ve Denge Üzerine Etkisi, Yüksek Lisans Tezi, Atatürk Üniv 